\title{
The Industry Scholars Mentorship Program: a Professional Industry Con- nection Experience for Engineering Undergraduates
}

\section{Dr. Breanne Przestrzelski, University of San Diego}

Bre Przestrzelski, PhD, is a post-doctoral research associate in the General Engineering department in the Shiley-Marcos School of Engineering, where she innovatively integrates social justice, humanitarian advancement, and peace into the traditional engineering canon.

Before joining USD in August 2017, Bre spent 9 years at Clemson University, where she was a three-time graduate of the bioengineering program (BS, MS, and $\mathrm{PhD}$ ), founder of The Design \& Entrepreneurship Network (DEN), and Division I rower. In her spare time, Bre teaches design thinking workshops for higher education faculty/administrators at the Stanford d.School as a University Innovation Fellow, coaches a global community of learners through IDEO U, and fails miserably at cooking.

\section{Dr. Chell A. Roberts, University of San Diego}

Chell A. Roberts is the founding dean of the Shiley-Marcos School of Engineering at the University of San Diego. He assumed his duties in July of 2013. He was also recently appointed as the Associate Provost of Professional and Continuing Education.

As an engineering dean at USD, Dr. Roberts has led the development of a new school of engineering, developing innovative engineering space, growing a world class faculty, and creating a base of industry and community partners. He also led a team to win a \$2 Million NSF Grant to revolutionize engineering education. The award focuses on creating "Changemaking Engineers" and seeks to transform the engineering mindset to infuse sustainability, social justice, peace, and humanitarian practices in the context of and professional skills of engineering.

Before joining USD, Roberts served as the Executive Dean of the College of Technology and Innovation at Arizona State University. While at Arizona State University, Dr. Roberts also had the opportunity to design an engineering program from a clean slate based on the study of best models of undergraduate engineering programs in the world.

Dr. Roberts received a PhD in Industrial Engineering from Virginia Tech, an MS Industrial Engineering degree and BA Mathematics degree from the University of Utah. 


\title{
The Industry Scholars Mentorship Program: a professional industry connection experience for engineering undergraduates
}

\begin{abstract}
Through an NSF-funded Revolutionizing Engineering Departments Grant, the University of San Diego and its industry partners are infusing engineering students with professional skills early in their undergraduate experience to uproot the trend of engineering graduates not meeting the industry demands. In Spring 2017, a year-long industry immersion program for top first- and second-year engineering undergraduates was driven into formation by the industry advisory board of the engineering school. This program (The Industry Scholars Program) is still in existence, impacting students professionally through workshops, industry site visits, and internships. The students that engaged in the first year of the immersion program are among those who have opted in for a new pilot program that builds on their experiences in the immersion program, but more focuses on one-on-one organize mentorship relationships between industry and students. The Industry Scholars Mentorship Program has been launched as of Fall 2018 and gives 13 third- and fourth-year students the opportunity to learn alongside a strategically matched mentor. This program was successfully piloted and initial activity from both mentors and mentees has been positive. This paper introduces the structure of the Industry Scholars Mentorship Program, shares initial output and lessons learned, and offers up a model for industry partners seeking to prepare and secure students equipped with both professional and technical skills.
\end{abstract}

\section{Introduction}

Current industry demands of engineering graduates are changing, and higher education is not producing students prepared for these careers in industry. This challenge for higher education has been present now for quite some time, as indicated by a 2014 Gallup Poll, where $96 \%$ of college provosts believe their graduates are ready for the workshop, but only a staggering $11 \%$ of business leaders feel that graduates have the competencies and skills necessary to succeed in the workplace [1]. This challenge does not escape engineering programs, and many are developing strategic programs to take on this industry readiness gap. Some engineering programs have launched industry-sponsored senior capstone programs while others bring industry influence into the classroom as guests, adjunct faculty or through industryinfluenced curriculum or professional socialization [2-5]. Other engineering programs have sought to close this industry readiness gap with mentorship programs [6-7].

Mentorship is a vital component to career advancement. It is stated by the Association for Talent \& Development, as shared through MentorCity, that $75 \%$ of industry executives point to mentorship as playing a key role in their career [8]. For engineering students, even if this value of mentorship is known, the process by which to find a mentor can be intimidating and awkward. For many, gender, race, and perceived self-efficacy define these limitations [9].

A year-long intentional industry mentorship program was developed at the University of San Diego to address this lack of workforce preparedness and intimidation around mentorship. The Industry Scholars Mentorship Program, was industry initiated and launched in Fall 2018, as a continuation of the Industry Scholars immersion program, also industry initiated but more focused on skillset development and hands- 
on industry experience. This paper introduces the structure of the Industry Scholars Mentorship Program, the developed programmatic elements, lessons learned, and initial output from participating industry mentors and university students, their mentees. The paper purpose is to illustrate this program so that others might be able to be inspired by and implement their own program based off the following learnings.

\section{Mentorship Program Formation}

The Industry Scholars Mentorship Program organically formed following the successful implementation of the year-long immersion pilot program, the Industry Scholars Program (ISP). In Fall 2016, the ISP was industry-initiated within an NSF-funded Revolutionizing Engineering and Computer Science Departments (RED) Grant at the University of San Diego, one of the goals of which was to infuse students with professional skills. The school industry advisory board, comprised of ten of the region's top companies in energy, computing, engineering design, mobility, consulting, and healthcare, saw the need for the development of the program and together drafted the following mission statement and program objective:

Mission statement: "The Shiley-Marcos School of Engineering at the University of San Diego proposes to create a professional skills program with our industry partners for first and second year undergraduate engineering students." The industry advisory board felt strongly about focusing on first and second year students because they felt this group has difficulty getting internship opportunities because their engineering skills have not been fully developed yet and could greatly benefit from industry mentorship during that time.

Objective: "Develop a professional and leadership skills development program with industry partners for first and second year high-performing engineering students" The industry advisory board also felt strongly about offering a program for high-performing engineering students, so as to have the first opportunity to secure their interest in future employment at their company.

From January 2017 through December 2017, the first ISP cohort of students attended industry-led monthly professional skills workshops and industry site visits during the academic school year and several students participated in summer-long internships. This first cohort contained 27 first and second year engineering students, 6 supporting faculty members, and 12 industry representatives to instill professional and leadership skills in these future engineers. Additional information about the formation of the ISP and its successful implementation in Year One can be found in previous publications [10].

As the second cohort of ISP launched in January 2018, program leaders and industry representatives sought to provide a follow-on program in which students from cohort one could continue to strengthen their professional skills and build on their ISP experiences. From this came the Industry Scholars Mentorship Program, a program that seeks to provide continued industry mentorship for graduated Industry Scholars and foster organic one-on-one mentorship relationships between industry and students. This program is also in its pilot-run year, having been launched in September 2018 and aiming to conclude in May 2019. It has been similarly driven by guidance from the industry advisory board of the school and exemplifies how industry partnerships in higher education are vital to increased preparedness of engineering graduates. 


\section{Mentorship Program Structure}

The academic year-long program itself could be segmented into three terms: (1) Program Preparation (2) Fall Mentorship and (3) Spring Mentorship as shown in Table 1.

Table 1: The year-long arc of the Industry Scholars Mentorship Program.

\begin{tabular}{|c|c|c|c|c|c|}
\hline Spring-Summer 2018 & \multicolumn{3}{|c|}{ Fall 2018 } & \multicolumn{2}{c|}{ Spring 2019} \\
\hline (1) Program Preparation & \multicolumn{2}{|c|}{ (2) Fall Mentorship } & \multicolumn{2}{c|}{ (3) Spring Mentorship } \\
\hline $\begin{array}{c}\text { Formation of committee, } \\
\text { recruitment of mentors, etc. }\end{array}$ & $\begin{array}{c}\text { Program } \\
\text { Kick-off }\end{array}$ & $\begin{array}{c}\text { Continued } \\
\text { Mentorship }\end{array}$ & $\begin{array}{c}\text { Mid-Program } \\
\text { Check-in }\end{array}$ & $\begin{array}{c}\text { Continued } \\
\text { Mentorship }\end{array}$ & $\begin{array}{c}\text { End-of-Program } \\
\text { Celebration }\end{array}$ \\
\hline
\end{tabular}

The (1) Program Preparation term began with initial planning between industry advisory board leaders and academic leaders in Spring 2018. In April 2018, the academic leaders presented a high-level program structure to the industry advisory board to receive feedback and extend an invitation to participate. The program was well-received by industry board members, many volunteered themselves or colleagues to participate as mentors, and a small mentorship program committee was formed to strategize program plans over the summer months. This committee was comprised of five industry advisory board members and two academic co-chairs (one the dean of the school and the other the post-doctoral student of the aforementioned grant) and communicated several times over the summer in making program decisions such as program expectations, mentorship policies, and mentorship support software.

There was much discussion around which, if any, mentorship software would best support the formation of the programming, in particular the match-making. Several platforms were explored at length and the software, MentorCity, a mentoring software for businesses, non-profits, and educational institutions, was decided to be that which the program moved forward with [11]. MentorCity offered many capabilities, and the feature most attractive to the mentorship program committee was that of the mentor:mentee match-making services that eased the pressure of making the perfect match by hand. The software completed this service by requiring all participating parties to complete a personal profile that logged answers to particular questions, which could be later used to make suggested matches. Some of the questions that were asked had multiple choice options to select from, while others invited free response.

A sample of these questions are below:

- (All) Three words that describe me are:

- (Mentor Only) Specialized skills: List the areas you feel comfortable mentoring someone in: options include: adaptability, communication, diversity/inclusion/gender in the workplace, networking, presentation skills, proactivity, problem solving, self-confidence, innovation, collaboration, leadership

- (Mentee Only) Development areas: List the areas you are seeking to develop: options include: adaptability, communication, diversity/inclusion/gender in the workplace, networking, presentation skills, proactivity, problem solving, self-confidence, innovation, collaboration, leadership 
- (Mentor Only)Current Industry:

- (Mentor Only) Current Job Function:

- (Mentee Only) Major:

- $\quad$ (Mentee Only) Preferred mentor gender:

The final list of questions asked of each participant was agreed upon by the committee and had influence from both MentorCity as well as other mentorship platforms that the industry board representatives had more familiarity with. It should be noted that the majority of questions were the same for those seeking to be a mentor or a mentee, but a select number of questions were reserved for only either those becoming mentors or those seeking mentorship. Therefore, one of the first questions required the responder to indicate which role they were seeking.

Once the platform was prepared, invitations to participate in the program were sent to all of the former consistently attending Industry Scholar students. To indicate their serious interest and then commitment to the program, the students were asked to complete their MentorCity profile and also attend the Program Launch Night to be held a month later. Students were given 10 days to complete their profile, after which time, the student portal to complete profiles expired. This was required because the student responses directly affected the profile questions asked of mentors. Final program preparation invited industry advisory board members to nominate those they felt would make great mentors for this program. Some nominated themselves, while others nominated up to four others. These nominations formed the initial invitation list to become a mentor in the pilot-run of the program, to which mentors were also required to indicate their intention to participate by completing their MentorCity profile and attend the Program Launch Night. Once all mentors and mentees completed their profiles, the post-doctoral academic cochair managed the mentor:mentee match-making, a process that took over a week to accomplish even with the assistance of the MentorCity software. Two mentors ended up not being matched as there were two less students than industry members that indicated their desire to participate. Once matches were made, the program participants were alerted by email to inform them of their match and provide the contact information of their match to make initial contact digitally before the program kickoff to be held the following week.

The first cohort of 13 students includes 6 third-year and 7 fourth-year students, all returning from their year-long participation in the first program run of ISP. The major of study balance between these 13 students was as follows: 6 mechanical engineering, 1 electrical engineering, 2 computer science, 3 industrial and systems engineering, and 1 student double majoring in computer science and electrical engineering. Twelve of the thirteen students have been fully participating in the program for Fall 2018, attending both in-person program engagements, while the thirteenth student participated fully from afar, studying abroad in Australia, but connecting digitally over video-conference when needed.

The first cohort of 13 mentors includes industry representatives with a wide range of mentorship experience, for some this being their first time mentoring and for others nothing different from what they do every day at their workplace. Their industry expertise ranges as well, including disciplines such as aviation, aerospace, computer soft/hardware, entrepreneurship, informatics/information science, marketing, advertising, venture capital, private equity, non-profit organization management, energy, design, renewables/environment, mobility, mechanical engineering, and industrial engineering. Their 
current industry positions included senior group managers, principal engineers, a president, a board member, a product designer, a vice president, and a deputy to the director.

The (2) Fall Mentorship term started with a semester (and program) kickoff event (Oct 2018) where the students and mentors were welcomed to the program by the academic co-chairs and met their respective mentor or mentee for the first time. For those mentees or mentors that were unable to attend in person (several were not geographically located in the university region), their matched mentor or mentee was required to make video contact with them at the start of the kickoff event.

The kickoff event began with an overview of how the Industry Scholars Mentorship Program started, beginning with the formation of the Industry Scholars Program. This provided an important foundation of knowledge for the industry mentors who were not previously involved with the ISP or the University of San Diego. The Mentorship Program objectives were then shared with the kickoff attendees:

- To provide continued industry mentorship for graduated Industry Scholars

- To foster organic one-on-one mentorship relationships between industry and University of San Diego students

Following a short discussion about the objectives of the program, mentors and mentees each shared a bit about themselves, their career journeys/hopes, and what they hope to get out of this mentorship program. Mentors and mentees were then guided through an interactive exercise discussing the importance and impact of mentorship, both on the mentor and mentee. Industry Scholars Mentorship Program logistics and expectations were then communicated:

- $\quad$ Length of relationship: Fall 2018-Spring 2019

- Meetings:

- At least once per month for $45+$ min ("in person")

- Mentee will share professional agenda/minutes

- $\quad$ Mentee to log any meeting cancellations (in MentorCity)

- Confidentiality \& Professionalism: Strictly professional relationship

- Goals: to be agreed upon by each mentor:mentee pair

Once all expectations were introduced and discussed, the mentors and mentees were guided through a short tutorial of the MentorCity platform and features they might be able to use to elevate their mentorship experience. One required feature for each mentor:mentee pair, to be completed that evening before their departure, was discussion and submission of the Mentorship Program Agreement, which was available on the platform and contained questions/topics for discussion as follows:

- (A) Meeting Formats - How would you like to meet? Would you like to have some meetings inperson and some over the phone/video conference? (B) Frequency of meetings - Would you like to meet weekly, biweekly, or monthly? (Mentorship Program requirement: At least 8 meetings total, minimum 1 a month)

- (A) Availability - What days and times typically work for each of you to meet? (B) Time of meetings - Will your meetings be 45 minutes, 60 minutes, or 60+ minutes in length? (Mentorship Program requirement: at least 45 min per meeting) 
- Length of relationship - How long are both of you willing to commit to this relationship? (Mentorship Program requirement: the duration of this academic school year (Fall $2018+$ Spring 2019). This period will be evaluated every 3-6 months.)

- Cancellations - What is the best way to notify each other in case a meeting needs to be postponed? Will you use MentorCity messages to notify each other of changes? What is the length of notice required if unable to keep a meeting appointment? (Mentorship Program requirement: Mentee is responsible for logging the cancellation in the MentorCity system.)

- (A) Agendas - How will the mentee share an agenda prior to each meeting? The professionallyformatted agenda can include updates, specific discussion topic(s), action items and setting the next meeting date. (B) Minutes - How will the mentee document and share minutes from each meeting? These professionally-formatted meeting minutes can include highlights of the conversation, what stood out to the mentee, and follow-up/action items.

- Confidentiality - Discuss how confidential information will be handled. What are some concerns around confidentiality to be considerate of?

- Feedback - How will the mentor provide honest and provide constructive feedback to the mentee? How will the mentee best receive this feedback?

- Goals - You both will discuss formal goals at a later meeting. For now, share your intentions of joining this Mentorship Program and what you hope to walk away from this program with.

- Additional Information - Anything else you wish to discuss before your formal mentor-mentee relationship begins?

At the conclusion of the kickoff event, mentors and mentees were invited to answer the following two questions as a base for their start in the program.

(1) What are you most hoping to get out of this program?

(2) What about tonight most stood out to you?

Mentorship commenced for the semester, with the occasional digital communication through the MentorCity platform or via email. Interaction data (ex: mentoring minutes, number of messages sent) was monitored by the post-doctoral academic co-chair via MentorCity and no alarming data points required the intervention of the co-chair. Special attention was paid for signs of disagreement between mentor and mentee or lack of participation by one of the parties.

The Fall Mentorship term concluded with a mid-program check-in event (Dec 2018) to which all mentors and mentees were required to attend. This event aimed to serve as a physical check-in with program participants, an opportunity to obtain feedback on the pilot program, and make necessary changes for the Spring semester as needed. Mentors and mentees were invited to revisit their initial goals stated in Oct 2018. An interactive exercise guided mentors and mentees through a series of peer-to-peer reflections:

- Reflect on the role you've played thus far. What has worked for you in your mentorship relationship?

- Reflect on the role you've played thus far. What hasn't worked for you in your mentorship relationship? 
Following discussion in their peer groups, each group was invited to share with the other group (the mentees then shared with the mentors and vice versa). Following discussion, the peer groups reformed to discuss the following:

- What stood out to you about the other group's responses?

- What might you be able to do to assist in the "hasn't worked for (them)" category?

- What will you commit to doing to make this happen?

Following this discussion in their peer groups, each group was again invited to share with the other group.

At the conclusion of this discussion, participants were reminded of the program expectations and invited to answer the following two questions:

(1) Two months in, what are you most hoping to get out of this program?

(2) What about tonight most stood out to you?

This concluded the second term of the program. At each of these program events, the responses to each question were collected and have been coded for evaluation of program progress. However, due to the low number of participants, no statistical significance can be drawn from the data, but can and will be used as a baseline to compare later programs that will scale.

The (3) Spring Mentorship term will not begin with any in-person event but rather will mostly consist of continuous mentorship with the occasional program check-in from the academic co-chairs. The only event that is planned to be held is that of the official End-of-Program Celebration, aiming to gather final participant feedback on the program and celebrate the conclusion of a required mentorship relationship as well as the hopeful continuation of a voluntary one. Because this event will not be conducted until late Spring 2019, there is no data to be shared from this event.

\section{Participant Response at Program Kick-off}

Approximately 91\% (21/23) of all program mentors/mentees participated in the baseline questions asked in-person at the conclusion of the program kick-off: "What are you most hoping to get out of this program?" and "What about tonight most stood out to you?" However, because two mentors were not present at the program kick-off, $100 \%(21 / 21)$ of those who were present participated in answering the questions.

Both mentors and mentees responded to "What are you most hoping to get out of this program?" and their answers were not separated for evaluation, though it was clear from some of their response content the role they play in the program. In Table 2, responses to the question "What are you most hoping to get out of this program?" are coded. It should be noted that each response could be given more than one code, and eight responses were tagged with two codes, totaling the number of codes to 29 , as indicated in the table below. 
Table 2: Coded responses to "What are you most hoping to get out of this program?" at the Oct 2018 program kick-off event

\begin{tabular}{|l|c|}
\hline \multicolumn{1}{|c|}{ Code } & Number of Appearances in Responses \\
\hline Personal development & $4 / 29(14 \%)$ \\
\hline New talent potential & $2 / 29(7 \%)$ \\
\hline Professional development & $6 / 29(21 \%)$ \\
\hline Giving back to the mentee & $7 / 29(24 \%)$ \\
\hline Networking and relationship building & $4 / 29(14 \%)$ \\
\hline Industry guidance (both giving and receiving) & $6 / 29(21 \%)$ \\
\hline
\end{tabular}

The most common response at nearly $25 \%$ was that given by mentors, who saw value of giving back to their mentee during the program duration (e.g. "opportunity to pour into a future engineer and learn from his passion"). Six responses mentioned valuing professional development (e.g. "relevant professional insight from my mentor") and another six looked forward to giving or receiving industry guidance (e.g. "learn from my mentor's experience so I can use their knowledge to succeed"). Four responses highlighted networking and relationship building (e.g. "make a new friend to add to my network") and another four shared their excitement for potential personal development coming from both mentor as well as mentee (e.g. "to have a greater confidence in my own ability and how I can leverage my skills in my career" and "how to be a non-technical mentor"). Finally, two responses documented their hope of getting new talent out of this program (e.g. "opportunity to meet great talent").

In Table 3, responses to the question "What about tonight most stood out to you?" are coded. It should be noted that each response could be given more than one code, but only two responses were tagged with two codes, totaling the number of codes to 23 , as indicated in the table below.

Table 3: Coded responses to "What about tonight most stood out to you?" at the Oct 2018 program kickoff event

\begin{tabular}{|l|c|}
\hline \multicolumn{1}{|c|}{ Code } & Number of Appearances in Responses \\
\hline Well matched and already connecting & $7 / 23(30 \%)$ \\
\hline Mentor/mentee enthusiasm & $9 / 23(39 \%)$ \\
\hline Impressive mentor caliber & $1 / 23(4 \%)$ \\
\hline $\begin{array}{l}\text { Program structure and University of San Diego } \\
\text { investment }\end{array}$ & $3 / 23(13 \%)$ \\
\hline Tasty food & $1 / 23(4 \%)$ \\
\hline Mentor investment & $2 / 23(9 \%)$ \\
\hline
\end{tabular}


The most common response at nearly $40 \%$ was given by both mentors and mentees, who saw impressive enthusiasm from the people in the room with them (e.g. "the amazing showing of eager mentees who are very engaged in this program" and "how willing and excited my mentor was to help"). The second most common response highlighted the surprise as how well matched and connected the mentors and mentors already were after just two hours together, in big things and small (e.g. "how well matched my mentee and I are on goals and ideas" and "we share awesome dads"). These two areas made up nearly $70 \%$ of all responses. The next most common response only was seen in three cases, but were those that commented on the Industry Mentorship Program structure or the University of San Diego investment in its students (e.g. "the way University of San Diego looks to develop and provide opportunities for their students" or "Seems like a very well organized program!"). Three other categories were seen in two or less responses: impressive investment by mentors in their mentees (e.g. "the personal investment my mentor has put into me thus far" and "the willingness of industry mentors to spend their own time with us"), the surprising caliber of the collective mentor line up (e.g. "high caliber of mentors"), and the surprisingly good food, as connected to a more detailed response (e.g. "Fantastic and passionate folks! And great food!").

Collectively, the responses to the above two questions show an eagerness for their invitation to participate in the program to grow in their personal and professional skills but also to connect (as many of them already did on this first night) with a mentor/mentee from which they can learn a great deal.

\section{Participant Response at Mid-Program Check-in}

Approximately $78 \%$ of all program mentors/mentees (18/23) participated in the first baseline question ("Two months in, what are you most hoping to get out of this program?") and 70\% (16/23) in the second question ("What about tonight most stood out to you?") when asked at the conclusion of the mid-program check-in. However, there were two mentors and one mentee unable to join for the mid-program check-in, altering this total to $90 \%(18 / 20)$ who participated in answering the first question and $80 \%(16 / 20)$ who participated in answering the second question.

In Table 4, responses to the question "Two months in, what are you most hoping to get out of this program?" are coded. It should be noted that each response could be given more than one code, and two responses were tagged with three codes and three responses were tagged with two codes, totaling the number of codes to 26 , as indicated in the table below. In the spirit of reflecting on their previously stated goals as the participants did at this mid-program check-in, the codes that were established for this question when asked during the program kick-off event (as shown above in Table 2) were kept and several others were added where appropriate. 
Table 4: Coded responses to "Two months in, what are you most hoping to get out of this program?" at the Dec 2018 Mid-Program Check-in event vs those at the Oct 2018 Program Kick-off

\begin{tabular}{|l|c|c|}
\hline \multicolumn{1}{|c|}{ Code } & $\begin{array}{c}\text { Number of Appearances in } \\
\text { Responses (during Mid- } \\
\text { Program Check-in in Dec } \\
\text { 2018) }\end{array}$ & $\begin{array}{c}\text { Number of Appearances in } \\
\text { Responses (during Program } \\
\text { Kick-off in Oct 2018) }\end{array}$ \\
\hline Personal development & $2 / 26(8 \%)$ & $4 / 29(14 \%)$ \\
\hline New talent potential & $1 / 26(4 \%)$ & $2 / 29(7 \%)$ \\
\hline Professional development & $4 / 26(15 \%)$ & $6 / 29(21 \%)$ \\
\hline Giving back to the mentee & $3 / 26(12 \%)$ & $7 / 29(24 \%)$ \\
\hline $\begin{array}{l}\text { Networking and relationship } \\
\text { building }\end{array}$ & $3 / 26(12 \%)$ & $4 / 29(14 \%)$ \\
\hline $\begin{array}{l}\text { Industry guidance (both giving } \\
\text { and receiving) }\end{array}$ & $3 / 26(12 \%)$ & $6 / 29(21 \%)$ \\
\hline $\begin{array}{l}\text { Increasing the relationship with } \\
\text { mentor/mentee }\end{array}$ & $6 / 26(23 \%)$ & - \\
\hline $\begin{array}{l}\text { Specific skill development with } \\
\text { mentor/mentee }\end{array}$ & $2 / 26(8 \%)$ & - \\
\hline Industry best practices & $2 / 26(8 \%)$ & - \\
\hline
\end{tabular}

While still high at $12 \%$ in Dec 2018, the most common response from Oct 2018 (giving back to the mentee) shifted to that of a newly coded category: increasing the current relationship with the mentor/mentee. The addition of this new category suggests that mentors and mentees were not yet satisfied with their relationship with their mentee or mentor, whether that being because they have a good relationship and are looking to build on it or that they might not have put much effort into their relationship thus far and are wanting to do so now. It was not clear from the responses how many of which type of relationship growth most were responding about. Examples of what was coded in this category include: "Getting to know mentee better so as to be more helpful to him". Professional development still came in as the second most popular category (e.g. "continued improvement of my skills and a better understanding of how I can improve my professional self"). Closely following with $12 \%$ were three categories: giving back to the mentee (e.g. "satisfaction of helping a younger engineer develop and flourish"), networking and relationship building (e.g. "I am hoping to expand my network to encompass not only my mentor, but also his mentors/peers to facilitate future professional relationships") which dropped $2 \%$ between the two data collection points and industry guidance (both giving and receiving) (e.g. "A valued new professional relationship and the tools to succeed in the transition from college to industry") which dropped $9 \%$ but might have been redistributed to the last two of the new categories. Personal development (e.g. "To learn more about what it's like in the industry and to grow professionally and personally") contributed $8 \%$ of responses, as the last two new categories: specific skill development with mentor/mentee, which aimed to capture the responses that definitively stated a 
skillset(s) they were looking to improve (e.g. "Be able to lead normal conversations in a casual yet respectful voice with my mentor") and best practices learned from industry (e.g. "industry best practices").

The above responses to the question "Two months in, what are you most hoping to get out of this program?" do suggest that some program participants have reevaluated their goals or have made them more defined. It is unclear if these reframed goals were influenced by the time in the program, the content shared at the mid-program check-in, or just being asked a second time.

In Table 5, responses to the question "What about tonight most stood out to you?" are coded. It should be noted that each response could be given more than one code, but only two responses were tagged with two codes, totaling the number of codes to 18 , as indicated in the table below.

When assessing the responses, the same codes, those initially evaluated in Table 3, were included as an option by which to code the new Dec 2018 responses, but it can be seen that these 5 original codes were only used in 4 of the 18 appearances, and only 3 of the 6 codes were seen at all. There were 6 new code categories added for this set of responses to what stood out to the program participants after their involvement in the mid-program check-in.

Table 5: Coded responses to "What about tonight most stood out to you?" at the Dec 2018 Mid-Program Check-in event

\begin{tabular}{|l|c|c|}
\hline \multicolumn{1}{|c|}{ Code } & $\begin{array}{c}\text { Number of Appearances in } \\
\text { Responses (during Mid- } \\
\text { Program Check-in in Dec } \\
\text { 2018) }\end{array}$ & $\begin{array}{c}\text { Number of Appearances in } \\
\text { Responses (during Program } \\
\text { Kick-off in Oct 2018) }\end{array}$ \\
\hline $\begin{array}{l}\text { Well matched and already } \\
\text { connecting }\end{array}$ & $1 / 18(6 \%)$ & $7 / 23(30 \%)$ \\
\hline Mentor/mentee enthusiasm & $2 / 18(11 \%)$ & $9 / 23(39 \%)$ \\
\hline Impressive mentor caliber & $0 / 18(0 \%)$ & $1 / 23(4 \%)$ \\
\hline $\begin{array}{l}\text { Program structure and } \\
\text { investment }\end{array}$ & $0 / 18(0 \%)$ & $3 / 23(13 \%)$ \\
\hline Tasty food & $0 / 18(0 \%)$ & $1 / 23(4 \%)$ \\
\hline Mentor investment & $1 / 18(6 \%)$ & $2 / 23(9 \%)$ \\
\hline $\begin{array}{l}\text { Use of the platform, } \\
\text { MentorCity }\end{array}$ & $3 / 18(17 \%)$ & - \\
\hline $\begin{array}{l}\text { Open and honest shared } \\
\text { dialogue }\end{array}$ & $2 / 18(11 \%)$ & - \\
\hline Meeting each other in-person & $1 / 18(6 \%)$ & - \\
\hline
\end{tabular}




\begin{tabular}{|l|c|c|}
\hline Current success of the program & $1 / 18(6 \%)$ & - \\
\hline Revisiting goals & $3 / 18(17 \%)$ & - \\
\hline $\begin{array}{l}\text { Commitment to making a } \\
\text { change in behavior }\end{array}$ & $4 / 18(22 \%)$ & - \\
\hline
\end{tabular}

The most common response seen after the Dec 2018 mid-program check-in was that of the category where mentors and mentees were committing to making a change in behavior following what they experienced at that event. This suggests that the mid-program check-in was a powerful event that brought about thought for change in several program participants. Examples of responses coded as such are: "My need to commit more of my time and effort into this program." and "The mentors' and mentees' commitments to be persistent and improve things that might not be working and expand upon things that are working." Three responses noted finding importance in revisiting goals as was conducted at the midprogram check-in (e.g. "there is value in reviewing goals periodically") and another three shared their realization of the importance of MentorCity as the platform tool to better utilize (e.g. "how important MentorCity is to the program"). Two responses commented on the shared dialogue between mentors and mentees as guided in the discussion activity for the night: "the open conversation and honest conversations". One response did give kudos to the clear success of the program at the mid-way point (e.g. "things are generally working for all participants") and one response celebrated getting to meet their mentee for the first time in person (e.g. "getting to meet my mentee in person (an excited emoji)"). This mentee was that who had been studying abroad in Australia for the majority of the Fall semester-- so this mid-program check-in afforded them an opportunity to meet face-to-face before the conclusion of the Fall Mentorship term.

Collectively, the responses to the above two questions show a continued interest and commitment to the program by both mentors and mentees. The mid-program check-in afforded a discrete time for reflection and connection between mentors, mentees, and their peer groups.

\section{Participant Activity (up to Dec 2018)}

The MentorCity platform collects statistics of participant activity and the following data was collected in early December 2018. While this time stamp is only two months into the program, it represents the activity able to be completed by mentor:mentee pairs in just two months' time.

In Table 6, the mentoring minutes as self-reported by each mentor:mentee pair is shown. One average showcases the average of all pairs (116.54 minutes), and the other average shares the average of the pairs who have reported their time (137.73 minutes). It is important to show both averages as not all pairs are as active on the platform in their self-reporting as some of their peers. 
Table 6: Two average self-reported mentoring minutes experienced by the mentor:mentee pairs: one that incorporates those who are not properly reporting their time on the MentorCity platform and the second that eliminates the reports of zero minutes.

\begin{tabular}{|c|c|}
\hline Average Documented Mentoring Minutes & $\begin{array}{c}\text { Average Documented Mentoring Minutes } \\
\text { (eliminating those who have 0 minutes) }\end{array}$ \\
\hline $116.54 \pm 73.52$ & $137.73 \pm 58.91$ \\
\hline
\end{tabular}

The above data shows that even in the two months (Oct 2018 and Nov 2018) all of the mentoring pairs were able to achieve their minimum requirement of 45 minute meetings each month (totaling 90 minutes required). The averages suggest that even including those who have not self-reported their mentoring minutes have participated in nearly 30 minutes more time than which is required, and over 45 minutes more time than which is required for those who have been consistently self-reporting their time. However, the reported range of mentored minutes is 60-300 minutes, as indicated by the standard deviation, with only one pair reporting under the requirement of 90 minutes, one pair reporting exactly 90 minutes, and all others reporting 120 minutes or more. The values of these mentoring minutes suggests that the majority of the mentorship pairs are exceeding their level of participation in the program. However, those who are not self-reporting their mentoring time and those who have reported under the requirement (just the pair that reported 60 minutes) will be followed up with individually.

\section{Mid-Program MentorCity Participant Output}

As was stated previously, mentorship pairs were invited to utilize the MentorCity platform as a tool to set goals and communicate regularly. It was observed during the Mid-Program Check-in that many pairs had not understood the value that MentorCity brought to the program and therefore had moved to other forms of common communication (ex: email, text, or phone). However, for those pairs that were more active on the platform some of their data was visible to the academic co-chairs, and two examples are shown below to illustrate the potential of this program.

All pairs were required to complete their mentorship agreement online and a segment of this agreement included a commitment to goals. Of those agreements submitted, the following two examples stood out as memorable: (1) "Mentor Goal: opportunity to bring you onto the staff Mentee Goal: someone to bounce things off of, to gain perspective from" and (2) "As a mentor, [Mentor] shared that he joined this program to "pay it forward" by passing along the advice and knowledge he has acquired in his roles. I [mentee] joined this program as a means of developing a continuous connection with a successful engineer who I can turn to for advice as I grow as an engineer, professional, and global citizen. We both joined this program excited to learn from one another. We hope to walk away from this program with a lasting connection, along with the valuable knowledge and skills we know we can gain from each other." It can be seen that even in these two examples, the form and level of detail of goals varied, as this portion of the agreement was free response to allow for this flexibility in response. However, both of these responses showcase that the relationship goals were clearly via a discussion between the two individuals, suggesting a more definite goal to which each party could work towards. 
A second data point to be showcased is that of the agenda and meeting minutes that the mentees were required to complete prior to and after each mentor meeting. The following is an example:
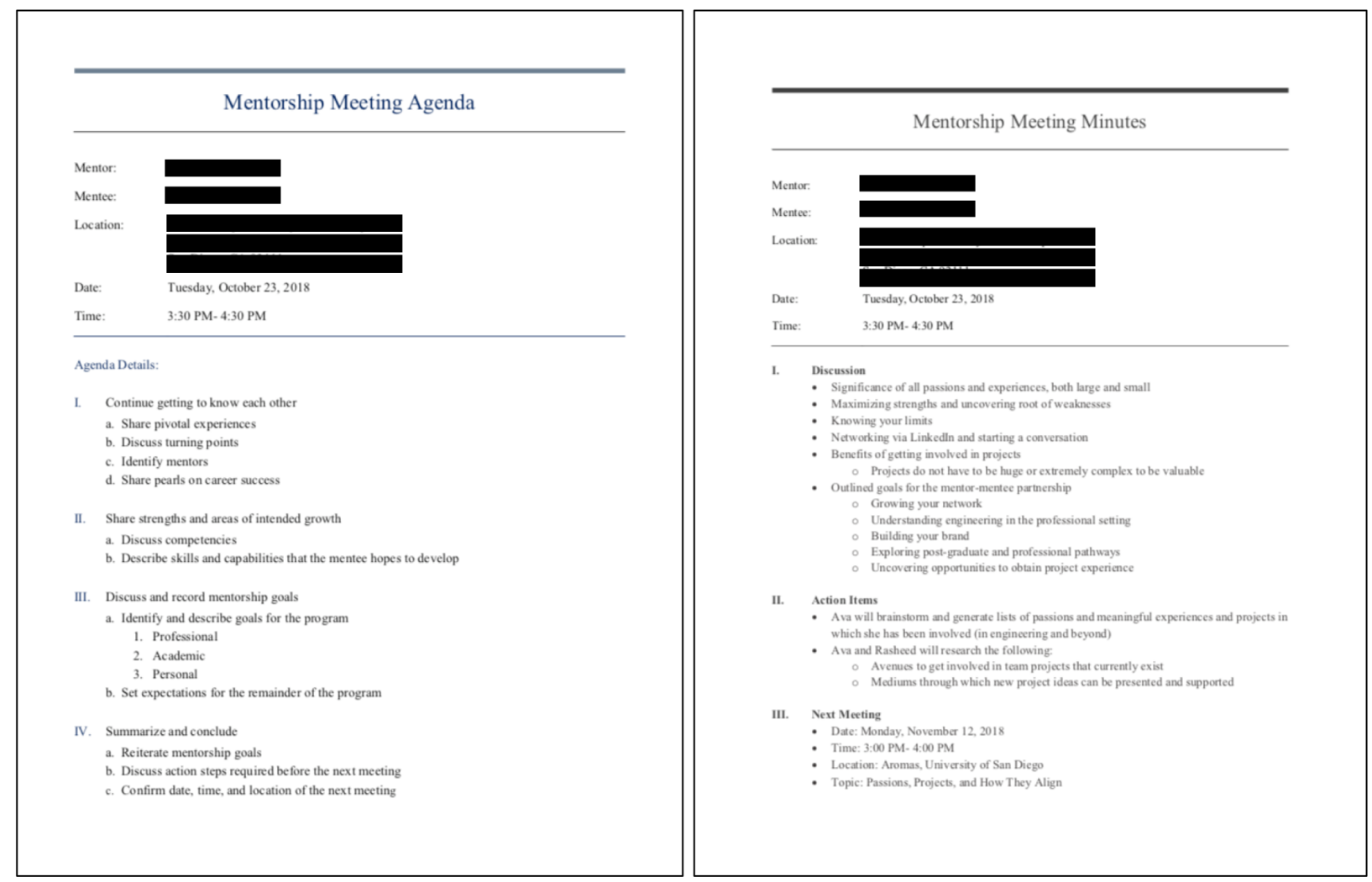

Figure 1: An example agenda document and meeting minutes document from a mentee

The above agenda showcases an example of what a mentee provided their mentor before their first inperson mentorship meeting. The students did not receive any formal in-person instruction on what a professional agenda looked like but rather were connected to several reference documents both on and off the MentorCity platform. Additionally, the above minutes document shows an example of what this same mentee shared with their mentor following that meeting. It is a sufficiently professional document for a third-year engineering student even though this student did not receive formal instruction on preparation of this document. It will be interesting to note how the level of professionalism in their documentation changes over the course of the program.

All of the above results showcase the mid-program success of the Industry Scholars Mentorship Program, a program organically born from engineering industry influence and implemented with thoughtful consideration from both industry and academic partners.

\section{Lessons Learned}

The above data represents the current assessment of the program, which will conclude in May 2019. After this time, more reflections on data and the program itself can be made. At this point in the program, the following lessons have been learned and will affect immediate future cohorts of the program. These 
lessons also serve as sources of inspiration for others to incorporate directly into mentorship programs of their own.

The in-person first meeting of the mentor and mentee was a critical touchpoint for initial connection, and the structured program launch for this first contact facilitated that connection well. In the future, the program co-chairs will continue using this program launch as the site for first meeting as opposed to suggesting a first meeting outside of the structured guidance. However, as participation scales, this might place timing constraints on the program timeline, possibly limiting the concept of incorporating rolling matches over a longer time period as mentors and mentees join. These concepts will have to be prototyped to see which resonates more with the participants' needs.

Matching of mentors and mentees by the post-doctoral academic co-chair was burdensome even with the assistance of the MentorCity software. It is suggested for others aiming to implement a mentor:mentee matching process to allot more time than expected to make the matches, especially with enough time from the launch of the program itself to avoid matches that might not be as intentionally matched under the time constraint. Because of the smaller numbers this program was serving, the co-chair was able to intentionally match each pair in the allotted time, but if the program had grown by even 5 pairs, this might not have been enough time.

In the future, the expected interaction with the mentor relationship software of choice will be more clearly communicated to mentees and mentors. This was done in Dec 2018 and clearly resonated with many in the room, standing out in $17 \%$ of the responses for that mid-program event. In the future, it will be recognized that the easier mode of communication for many of the mentors and mentees is not a separate platform, but rather something they already are accustomed to using (i.e. text, email) and other platforms to measure this communication are already being looked into. Additionally, the required agendas and minutes produced by the mentors were not found to be as important to share with the program co-chairs, so these documents will be kept between the mentor and mentee for confidentiality purposes.

Something that stood out was the mentor's lack of emphasis placed on connecting with potential future employees as being a main reason for their participation in the program. The value placed on "new talent" itself dropped between October and December, which might point to different personal values that matter more to mentors when giving back to the students. This suggests that the profile of the ideal future mentor also holds this value as less important than others that were named more frequently. Identifying the ideal mentor profile and mentee profile is one that will be further explored as the program continues to take shape.

\section{Conclusion}

The Industry Scholars Mentorship Program successfully piloted its first cohort of students in Fall 2018 and continues to pilot this program in Spring 2019. Driven by industry professionals and a desire to support the continued professional development of Industry Scholars from the first cohort in 2017, the program has, as of the mid-way point, achieved its objectives to provide continued industry mentorship for graduated Industry Scholars and has fostered organic one-on-one mentorship relationships between industry and students. The mid-program results show promise for a successful second half 
implementation to be completed in May 2019, and the lessons learned are those that will continue to shape future cohorts of the program. The Industry Scholars Mentorship Program could be a model for industry partners seeking to prepare and secure students equipped with both professional and technical skills.

\section{Acknowledgements}

The authors would like to thank the students and the industry mentors in the Industry Scholars Mentorship Program for their participation and willingness to contribute to a new pilot program. The authors also acknowledge the support of the National Science Foundation through Grant 1519453.

\section{References}

[1] A. Grasgreen, (2014, Feb 27). Ready or Not: Are college graduates prepared for the workforce? Only university administrators think so. Inside Higher Ed.

[2] S.P. Magleby, R.H. Todd, D.L. Pugh, and C.D. Sorensen, "Selecting Appropriate Industrial Projects for Capstone Design Programs," in Int. J. Engineering Education, Vol 17, No 4 and 5, pp 400-405, 2001. [3] R.S. Weissbach, J.W. Snyder, E.R. Evans Jr., and J.R. Carucci Jr., "Industrial Sponsor Perspective on Leveraging Capstone Design Projects to Enhance Their Business," in American Journal of Engineering Education, Vol 8, No 1, pp 13-22, June 2017.

[4] G.D. Young, D.B. Knight, PhD, L.M. Warburton, and C.D. Ciccohn, "Developing Student-centered Partnerships: Professional Socialization and the Transition to Industry," in Proc. of the American Society for Engineering Education Annual Conference, New Orleans, LA, June 2016.

[5] D. Schmueser, J.O. Brooks, R.G. Prucka, and P. Pisu, "Innovative Graduate Engineering Education Implemented with Project-focused Learning: A Case Study- The Clemson University Deep Orange 3 Vehicle Prototype Program," in in Proc. of the American Society for Engineering Education Annual Conference, Salt Lake City, UT, June 2018.

[6] C. Poor, and S. Brown, "Increasing Retention of Women in Engineering at WSU: A Model for a Women's Mentoring Program,” in Col Stud Journal, Vol 47, No 3, pp. 421-428(8), Sept 2013.

[7] R.R. Pecen, PhD, F. Yildiz, PhD, and M. Albrecht, "An Effective Industry-University Partnership to Develop Tomorrow's Workforce," in Proc. of the American Society for Engineering Education Annual Conference, Salt Lake City, UT, June 2018.

[8] L. Balu and L. James, PhD, "Facilitating Employees Career through Mentoring Methods," in European Journal of Business and Management, Vol 8, No 7, 2016.

[9] M. Andrews, "A Systematic Literature Review of the Impact of Undergraduates Work Experiences on Women in Engineering," in Proc. of the American Society for Engineering Education Annual Conference, Salt Lake City, UT, June 2018.

[10] B. Przestrzelski, L. A. Perry, and C. A. Roberts, “The Industry Scholars Program: An Immersive Professional Experience for Undergraduates," in Proc. of the American Society for Engineering

Education Annual Conference, Salt Lake City, UT, June 2018.

[11] MentorCity. Mentoring Software. https://www.mentorcity.com 